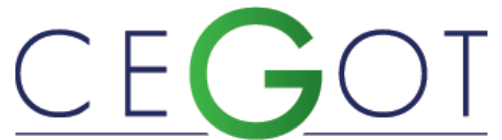

Centro de Estudos de Geografia e Ordenamento do Território
Geografia e Ordenamento do Território, Revista Eletrónica Centro de Estudos de Geografia e Ordenamento do Território http://cegot.org

MadeIRos, Heleriany

Universidade do Estado do Rio Grande do Norte- UERN

59600-000, Mossoró, Brasil (Rua Professor Antonio Campos, s/n, BR-110, km 48, Costa e Silva)

helerianymadeiros@hotmail.com

Grigio, Alfredo

Universidade do Estado do Rio Grande do Norte- UERN

59600-000, Mossoró, Brasil (Rua Professor Antonio Campos, s/n, BR-110, km

48, Costa e Silva)

alfredogrigio1970@gmail.com

PESSOA, ZORAIDE

Universidade Federal do Rio Grande do Norte- UFRN

59078-970, Natal, Brasil (CCHLA - Departamento de Políticas Públicas, Sala

02, 1ำ andar)

zoraidesp@gmail.com

\title{
Desigualdades e justiça ambiental: um desafio na construção de uma cidade resiliente
}

Inequalities and environmental justice: a challenge in building a resilient city

Referência: Madeiros, Heleriany; Grigio, Alfredo; Pessoa, Zoraide (2018). Desigualdades e justiça ambiental: um desafio na construção de uma cidade resiliente. Revista de Geografia e Ordenamento do Território (GOT), n. ${ }^{0} 13$ (junho). Centro de Estudos de Geografia e Ordenamento do Território, p. 247-265, dx.doi.org/10.17127/got/2018.13.011

\section{RESUMO}

O presente artigo objetiva refletir acerca da desigualdade ambiental como um desafio na construção de uma cidade resiliente. Para tanto, foi realizada uma pesquisa de caráter bibliográfico abordando os temas do processo de (re)produção das cidades, desigualdade ambiental e cidades resilientes. O artigo faz uma breve introdução acerca da contextualização dos problemas ambientais nas cidades, para depois passar por uma discussão teórica dos principais temas elencados. Traz como resultado a associação da problemática da desigualdade ambiental junto à construção dessas cidades, mostrando que, para se chegar a produção de uma cidade resiliente, não é necessário somente a ação de políticas governamentais, mas, também, a participação da população na tomada de decisões.

Palavras-chave: Desigualdade ambiental; Problemas socioambientais urbanos; Resiliência; Cidades resilientes.

\section{ABSTRACT}

The present study aims to discuss the environmental inequality as a challenge in the construction of a resilient city. For this purpose, a bibliographic research was carried out addressing the themes of (re)production process of cities, environmental inequality and resilient cities. The paper makes a brief introduction regarding the contextualization of environmental problems in the cities and then it goes through a theoretical discussion of the main topics listed. As a result, it brings in the association of the problematic of 
environmental inequality with the construction of these cities, showing that to reach the production of a resilient city, it is not enough to have actions from government policies, but also the participation of the population in the decision making is needed.

Keywords: Environmental Inequality; Social and Environmental Urban Problems; Resilience; Resilient Cities.

\section{Introdução}

Os problemas ambientais das cidades são frutos dos processos de urbanização rápida e intensa, e, por vezes, desordenada. Esse modelo de urbanização caracteriza as sociedades contemporâneas em contextos de países em desenvolvimento, como o Brasil, o que pode trazer dimensões complexas como consequências. Especialmente, em virtude de que grande parte das cidades existentes apresentam sérios problemas de infraestrutura urbana, o que torna seus espaços diferenciados, segmentados e vulneráveis. Entre as infraestruturas urbanas, a ausência de saneamento básico, descarte inadequado de resíduos sólidos, domicílios situados em lugares impróprios são exemplos, dentre tantos outros, dos problemas de planejamento urbano que acometem as populações, principalmente aquelas que possuem uma menor renda.

Em contextos de países cujos níveis de desenvolvimento são pouco igualitários e equitativos, independente de constituírem-se como sociedades capitalistas ou não, os problemas ambientais tornam-se desafios que requerem mudanças no direcionamento dos modelos de gestão dessas cidades. Um futuro de maior capacidade de resiliência e adaptação a cenários marcados por incertezas e riscos seria a direção para a qual as cidades deveriam seguir, já que estaríamos vivendo em uma sociedade de risco, como bem indica a análise de Beck (2011), em consonância com a perspectiva de ser consequências da modernidade (GIDDENS,1991).

Certamente que a ausência de planejamento urbano pode constituir-se em um dos fatores que levam as cidades, e as populações que nela vivem, a estarem mais vulneráveis. Consequentemente, passarem a estar mais expostas aos riscos múltiplos decorrentes de processos desordenados de ocupação territorial, estruturas sociais pouco efetivas. Além disso, há fatores naturais, que perderam o caráter de fenômenos naturais raros e tornaramse mais frequentes, tais como chuvas torrenciais, terremotos, períodos de estiagens 
prolongadas, entre outros, impondo maior capacidade de resposta da gestão das cidades. Os riscos, mesmo que pareçam ser marcas apenas das sociedades contemporâneas, também já existiam antes, mas a diferença é a frequência, intensidade e diversidade que se apresentam (BECK, 2011; GIDDENS,1991).

A probabilidade de riscos aumenta muito mais em contextos que, cuja a urbanização acelerada, somada a aglomeração de bens industriais e de serviços, bem como a falta de ordenamento territorial, políticas urbanas e gestão urbana, transformam as cidades em lugares de convivência reduzida. Como afirma Rattner (2009), esses fatores "têm transformado as cidades no oposto de sua razão de ser - um lugar para viver bem" (RATTNER, 2009, p.07).

Assim, percebe-se que em países como o Brasil, de desenvolvimento desigual, mesmo existindo políticas públicas e privadas voltadas ao planejamento e ordenamento das suas cidades, os gestores tendem a agir paliativamente quando confrontados por momentos de calamidade. Pensar e agir sob esse viés é, também, demonstrar a falta de organização com os gastos públicos, uma vez que se gasta mais em medidas de contenção ou mitigação do que em medidas preventivas. Mesmo as medidas de contenção ou mitigação são pouco efetivas e desconectadas da realidade locais em situações de desastres.

Nesse quadro de gestões urbanas ineficientes, cenários de riscos e a incerteza frente aos desastres ambientais, uma grande parte da população, principalmente aquela mais vulnerável aos riscos, adapta-se à realidade a qual está submetida. Assim, favelas são erguidas e espaços públicos são ocupados. Esses sujeitos, devido a essa condição de vulnerabilidade, são também aqueles que mais sofrem com a desigualdade, seja ela social ou ambiental.

Pensar nas cidades como espaços dinâmicos e que devem seguir um planejamento adequado é refletir sobre os diferentes atores que vivem nesse lugar. Qual a capacidade de resposta da população que é acometida por situações de desastres? Como a cidade pode adaptar-se e tornar-se resiliente frente aos problemas enfrentados pelo processo de urbanização desordenado? Refletir sobre esses questionamentos é confrontar aos modelos de sociedade na qual vivemos, excludente e degradante, que refletem o modo de reprodução econômica, que visa a acumulação de riquezas e a extração de recursos naturais. 
Busca-se, portanto, uma sociedade menos desigual socialmente e ambientalmente, com a finalidade de se tornar resiliente frente às intempéries impostas tanto pela ação da natureza, como pela ação antrópica.

Assim, esse artigo reflete sobre a relação entre a desigualdade ambiental e a resiliência nas cidades, através do embasamento em referenciais teóricos que analisam essas temáticas. Partimos do pressuposto que a resiliência nas cidades somente é possível se for pensada como um mecanismo de gestão urbana, atrelada à perspectiva de um ordenamento territorial que considere cenários de incertezas e situações de riscos em magnitude crescente no presente e futuro das cidades. Além disso, chega-se à conclusão de que esses dois eixos possuem uma ligação intrínseca nos debates acerca do crescimento e desenvolvimento das cidades, nas assimetrias e desigualdades que apresentam, particularmente no contexto das cidades brasileiras.

\section{Discussão teórica}

\subsection{O processo de (re)produção das cidades}

O processo de (re)produção das cidades é, de maneira geral, complexo, fato que pode ser explicado por uma de suas principais características: a dinamicidade. Construída através das mais diversas relações - mercantis, trabalhistas, sociais -, as cidades se configuram como palcos de inúmeros fenômenos, sejam eles sociais, econômicos e ambientais, que refletem a sociedade que vive em seus limites.

As cidades antigas - originadas na Ásia Menor, também conhecida por Anatolia, Europa Ocidental e Oriental - eram configuradas como grandes centros administrativos e comerciais, mantendo seus mercados através das relações de troca. Eram, também, na maioria das vezes, geridas por uma monarquia, e cenário de inúmeras guerras, que tinham por finalidade expandir seus territórios. No entanto, foi a partir do final do século XV e início do século XVI, com o fim do feudalismo e com o êxodo rural, que as cidades, segundo Lefebvre $(2001$, p. 12) passam a ser "centros de vida social e política onde se acumulam não 
apena as riquezas como também os conhecimentos, as técnicas e as obras (obras de arte, monumentos)".

Apesar disso, é com o início da industrialização - final do século XVIII - que as cidades ganham a característica de modernas, sendo o processo industrial o indutor das transformações da sociedade, apresentando, como um de seus efeitos, o processo de urbanização (LEFEBVRE, 2001).

Atualmente, as cidades, principalmente as de países denominados "em desenvolvimento", crescem de maneira rápida e desordenada, num processo de industrialização tardia, como ocorre no território brasileiro.

No contexto brasileiro, cujo processo de industrialização se inicia nas primeiras décadas do século XX, expande-se de forma mais densa a partir da década de 1950, vivendo um desenvolvimentista e de realocação da capital administrativa do país, da região Sudeste para o Centro-Oeste, durante o governo o Juscelino Kubistchek. Tal governo apresentava, como meta principal de gestão, o desenvolvimento econômico do país, tanto na área de infraestrutura (rodovias, hidrelétricas, aeroportos), quanto na área da indústria. A expansão industrial no país segue nas décadas seguintes, mesmo durante o período da Ditadura Militar entre 1964 a 1985, constituindo uma dinâmica industrial concentrada principalmente na região Sudeste e dispersa nas demais regiões brasileiras.

Desse modo, podemos inferir que o processo de urbanização das cidades brasileiras, de forma geral, ocorre não necessariamente impulsionada pela industrialização, mas, sobretudo, pela prestação de serviços como setor de dinâmica econômica predominante na maioria de suas cidades. Configura uma rede urbana de grande, médias e pequenas cidades, metrópoles e regiões metropolitanas, fragmentadas e com níveis de desenvolvimento social e urbano marcado por desigualdades.

É possível supor que a urbanização não diminuiu as distâncias sociais nas cidades, muito perceptível no caso brasileiro e também de outros países latinos americanos e do mundo como um todo. No cenário latino, o México, cuja urbanização se aproxima da realidade brasileira e dos níveis populacionais da rede de cidades constituídas por grandes centros urbanos inseridos na dinâmica global. As cidades de São Paulo, no Brasil, e a Cidade do México, no México, são exemplos de grande dinamismo urbano, regional e industrial, mas 
configura diferentes ritmos de urbanização em relação as demais cidades desses países. Estudos sobre o desenvolvimento urbano e regional desses países contribuem nessa direção, como as análises organizadas por Ribeiro e Ribeiro (2018) e UNikel (2016).

Esse crescimento desordenado e de urbanização precárias das cidades contribui para o que Beck (2011) denomina de "sociedade de riscos", uma sociedade que vive uma "crise civilizatória" em que as vias de desenvolvimento econômico fazem "surgir ameaças globais supranacionais e independentes de classe" (BECK, 2011, p.16). Além dos riscos, o processo de produção das cidades também gerou diversos problemas sociais, ambientais e culturais. Um desses problemas é o de desigualdades sociais, que se refletem no espaço urbano em função de cada contexto específico (VASCONCELOS, 2013). Nesse sentido, as relações sociais dentro do espaço, os riscos e problemas causados pelo mau planejamento urbano e territorial variam de acordo com o tempo e com as características da sociedade que ali convive.

Santos (2012, p. 323) afirma que "a cidade é um grande sistema, produto de superposição de subsistemas diversos de cooperação, que criam outros tantos sistemas de solidariedade". A cidade como um sistema é resultado também da ação de atores sociais e de suas atuações sobre ela, com suas diferenças sociais, econômicas e culturais, sendo estes também responsáveis pela construção da cidade. Essas diferenças são somadas aos modos econômicos ao qual estamos submetidos - seja o capitalismo ou outros -, que acabam por tornar escassos os bens naturais devido à necessidade de consumo produzida pelo sistema.

Nesse sentido, e como bem afirma Acselrad (2009), em crítica ao capitalismo, este modo de produção gera, além de desigualdades sociais, desigualdades residenciais dentro das áreas urbanas, sendo esta "[...] a condição da reprodução das desigualdades ambientais" (p.30), que segregam os indivíduos habitantes das cidades. Assim, criar cidades mais solidárias, mais acessíveis a toda população é um dos desafios das cidades sustentáveis, uma vez que, ainda segundo o mesmo autor, "os conflitos urbanos em torno dos 'bens coletivos', do 'espaço não mercantil' por meio do qual as práticas espaciais se confrontam na disputa por sua 'duração', são os sintomas vivos da insustentabilidade das cidades" (ACSELRAD, 2009, p.31). 
Acselrad (2009, p.39) também aponta que um dos desafios de se pensar a cidade como um sistema solidário e sustentável é:

tratar de pensar um novo modelo de desenvolvimento urbano, baseado nos princípios da democratização dos territórios, no combate à segregação socioespacial, na defesa dos direitos de acesso aos serviços urbanos e na superação da desigualdade social manifesta também nas condições de exposição aos riscos urbanos.

Posto que a reprodução das cidades é desigual e que a cidade não é para todos, refletiremos no tópico seguinte sobre a justiça ambiental e sua relação com a desigualdade para pensar as cidades.

\subsection{Justiça Ambiental e Desigualdade Ambiental}

A Justiça Ambiental pode ser compreendida como a defesa de que não haja desproporção na distribuição das consequências dos riscos decorrentes da problemática ambiental contemporânea. Caracteriza-se, também, como um movimento que emerge da evidenciação da problemática ambiental em todo mundo, que se difunde a partir da década de 1970 . Esse movimento se constitui numa extensão dos movimentos sociais tradicionais pelos direitos civis, pela igualdade racial e de classes existentes nos Estados Unidos da América, que passam a englobar os conflitos neste país decorrente das consequências dos problemas ambientais para as populações mais vulneráveis.

Nas décadas seguintes, essa percepção das consequências dos problemas ambientais sobre as populações mais vulneráveis (MARTíNEZ ALIER, 2009) se expande para outros países, dadas as evidenciações das situações de riscos decorrentes da constituição de uma nova ordem ecológica (FERRY, 2009). Institucionaliza-se a partir de uma série de eventos internacionais e estabelece novos parâmetros de conhecimentos e política ambiental global, nacional e local, haja vista que os problemas ambientais passam a compor as características das sociedades contemporâneas, marcadas pelo risco como consequências da modernidade (Beck, 1995; Beck, Lasch e Giddens, 1999; Giddens, 2000; Giddens, 2010).

Uma série de acontecimentos nos Estados Unidos da América foram decisivos para que as populações vulneráveis estivessem mais suscetíveis às consequências dos problemas ambientais, pois implica sobre as suas condições de vida diretamente. Entre as populações mais vulneráveis, destacavam-se as pobres, negras e imigrantes latinos (BULLARD, 1990). 
A partir do Movimento por Justiça Ambiental, cresce a percepção entre problemas ambientais e a manutenção das desigualdades sociais, que incidem diretamente sobre as consequências desses problemas e dos riscos que podem gerar as populações vulneráveis. Alguns eventos contribuíram para essa percepção, destacam-se o desastre ambiental do Love Canal, Niágara, Nova York, por contaminação química em residências, que atingiu 900 famílias na década de 1970. Outro evento ocorreu em 1982, quando foi descoberto que um aterro para depósito de solo contaminado por PCB (polychlorinated biphenyls) seria instalado na comunidade negra de Warren, Carolina do Norte. Esses dois casos, somam-se a outros eventos que foram descritos nos estudos de Bullard $(1990,1993)$ e que vão demarcar o racismo envolvidos nos conflitos ambientais nos Estados Unidos da América. Esse evento na Carolina do Norte marca, portanto, o nascimento do movimento por Justiça Ambiental (MARTÍNEZ ALIER, 2009).

Assim, a título de definição, pode-se compreender a Justiça Ambiental como sendo "a luta contra a distribuição desproporcional de dejetos tóxicos ou a exposição diante de diferentes formas de risco ambiental em áreas predominantemente povoadas por populações afroamericanas, latinas ou indígenas" (MARTíNEZ ALIER, 2009, p. 231). Ou seja, é um movimento que se refere às externalidades ambientais relacionadas ao racismo, cuja repercussão política é forte e conflituosa nos Estados Unidos "devido à larga tradição de luta pelos direitos civis" (MARTíNEZ ALIER, 2009, p.231).

Nos países da América Latina e em outros países que configurariam o Terceiro mundo, "a questão socioambiental mais instigante durante a década de 1980 era a que polemizava sobre a existência de um ambientalismo indígena em paralelo a um ecologismo dos pobres" (MARTínEZ ALIER, 2009, p. 231). Essa formulação se assentava no fato de uma crítica que os movimentos ambientais, inaugurados a partir da década de 1960 em todo mundo, eram constituídos por pessoas brancas, que discutiam os problemas na ótica urbana e passaram a constituir organizações ambientais caracterizadas por defender, principalmente, essas bandeiras. Martínez Alier (2009) destaca que poucas organizações ambientais passaram a incorporar em suas lutas o racismo ambiental, entre ela o Greenpeace e o Earth Island Institute.

No Brasil, o Movimento por Justiça Ambiental teve como marco inicial os estudos intitulados "Sindicalismo e Justiça Ambiental", elaborados pela Organização Não-Governamental Ibase, 
pela Central Única dos Trabalhadores - CUT - e por pesquisadores da Universidade Federal do Rio de Janeiro - UFRJ, no ano 2000. Esse trabalho culminou na realização do Seminário Internacional Justiça Ambiental e Cidadania, no ano de 2001, quando foi criada a Rede Brasileira de Justiça Ambiental. Nesse mesmo período, definiu-se os conceitos de justiça e injustiça ambiental (ACSELRAD, 2009). Já o conceito de desigualdade ambiental surge das diferentes teorias que abordam as questões de justiça, equidade e injustiça ambiental (MORATO, 2008).

Acselrad (2002) acrescenta, ainda, que o conceito de desigualdade ambiental surge junto as categorias de racismo ambiental, injustiça ambiental, discriminação ambiental, entre outras, no período que ele denomina de "momento subjetivista 1" da dinâmica do movimento de justiça ambiental, que também pode ser explicada pelo que o autor chama de "momento subjetivista 2", em suas palavras:

A apresentação de explicações para as situações de desigualdade ambiental passa a integrar as estratégias argumentativas que concorrem para a constituição de alianças potenciais com outros grupos sociais. A lógica segregadora é apresentada como o resultado da operação regular de dois mecanismos, evidenciados por duas proposições. De acordo com a primeira, a desigualdade social e de poder sobre os recursos ambientais estaria presente na raiz dos processos de degradação ambiental: quando os benefícios de uso do meio ambiente estão concentrados em poucas mãos, do mesmo modo que concentrada apresenta-se a capacidade de transferir 'custos ambientais' para os mais fracos, o nível geral de 'pressão' sobre o meio ambiente tende a não se reduzir. De onde, decorreria logicamente que a proteção do meio ambiente depende do combate à desigualdade ambiental: não se poderia enfrentar a crise ambiental sem promover a justiça social. A segunda proposição sustenta que em condições de desigualdade social e de poder sobre os recursos ambientais, bem como de liberdade irrestrita de movimento para os capitais, os instrumentos correntes de controle ambiental tendem a aumentar a desigualdade ambiental, sancionando a transferência de atividades predatórias para áreas onde é menor a resistência social. A solidariedade interlocal, eventualmente internacional, é justificada como forma de evitar a exportação da injustiça ambiental e de dificultar a mobilidade do capital, o qual tende correntemente a abandonar áreas de maior organização política e dirigir-se para áreas com menor nível de organização e capacidade de resistência. (ACSELRAD, 2002, p.57)

Para Torres (1997), a origem para a conceituação da desigualdade ambiental possui duas situações, afirmando ele que:

(...)Tanto existem situações onde o risco ambiental já está presente e as famílias 'optam' por se localizar neste espaço, quanto existem situações onde comunidades previamente instaladas são 'assaltadas' por 
empreendimentos não desejados, definidos em instâncias institucionais fora do controle destas comunidades. (TORRES, 1997, p.48).

Morato (2008) também afirma que o conceito de desigualdade ambiental liga-se à teoria do conceito de igualdade ambiental, de modo que tal conceito:

[...] expressa a situação em que tanto as amenidades ou aspectos positivos ligados ao ambiente, como os inconvenientes ou aspectos negativos fossem distribuídos igualmente entre a população. Quanto mais nos afastamos dessa condição teórica, maior é a desigualdade ambiental. (MORATO, 2008, p.48)

Portanto, como muitos outros termos e conceitos utilizados pela comunidade acadêmica, a concepção de desigualdade ambiental é complexa. Mas, segundo Morato (2008), o termo desigualdade ambiental é utilizado, pois apresenta isenção de juízo de valor, ou seja, não é porque algo é desigual que será justo ou injusto, mas se torna desigual, no sentido de injustiça, quando nem todos beneficiam com o que deve ser oferecido. No caso do cidadão brasileiro, a desigualdade ambiental, e também as outras manifestações dela, podem ser consideradas ilegais, já que o art. 5 da Constituição Federal garante que "todos são iguais perante a lei, sem distinção de qualquer natureza" (BRASIL, 1988). Entretanto, apesar da constitucionalidade, essa garantia segue a lógica de poder, sobretudo, o poder simbólico, marcado por assimetrias.

Partindo do exposto e, nesse contexto de planejamento inadequado das cidades, de não se pensar a cidade como um sistema e a depender das características que o modo de produção em que está inserida, é que a desigualdade ambiental se manifesta. A condição de vulnerabilidade e, consequentemente, a exposição da população aos riscos poderia ser evitada, se as desigualdades sociais, em países como o Brasil, não fossem tão gritantes. (HERCULANO, 2002)

A falta de acesso à informação também é um dos problemas que causam a desigualdade ambiental, verificando-se escassas iniciativas voltadas à conscientização de seus direitos e deveres enquanto cidadãos e à educação ambiental, principalmente das populações mais afetadas. Consequência disso é que as populações de baixa renda e afrodescendentes, homossexuais, indígenas, entre outros, são aqueles mais afetados pelo denominado movimento NIMBY (not in my backyard - não no meu quintal), sendo tais grupos alocados em lugares não desejáveis para se viver, consequentemente mais expostos aos riscos (TORRES, 1997; ACSELRAD, 2009). 
Torna-se evidente, assim, que a desigualdade ambiental se faz presente quando nem todos possuem condições de pagar por uma qualidade ambiental, pelo que se considera uma sociedade mais justa, onde todos possuam acesso, seja aos bens naturais, sociais, culturais e econômicos, para que as populações vivam em um mundo melhor. Pensando por esse ponto e no caminho em que as cidades vieram tomando ao longo de seu desenvolvimento, foi que se buscou o termo "resiliência", tendo como base as referências das ciências da Natureza.

\subsection{Cidades resilientes}

O conceito de resiliência e sua relação com o ambiente, como afirma Folke (2016), mais especificamente enfocando o estudo sobre ecossistemas, foi proposto por Holding (1973), quando ele se propôs entender a capacidade dos ecossistemas frente a alguma mudança. $O$ conceito de resiliência ainda é complexo, segundo Folke (2016, p.02):

In some fields the term resilience has been used in a narrow sense to refer to the return rate to equilibrium upon a perturbation. Others tend to interpret resilience as bouncing-back after disturbance or recovery time, or recovery to what you were before in more general terms. In this way of looking at the world there is often an implicit focus on trying to resist change and control it to maintain stability. The resilience approach of resilience thinking is much richer. It deals with complex adaptive system dynamics and true uncertainty and how to learn to live with change and make use of it.

Percebe-se, então, que o termo resiliência, assim como o de desigualdade ambiental, também possui suas dualidades. Ainda segundo o mesmo autor:

In popular terms, resilience is having the capacity to persist in the face of change, to continue to develop with ever changing environments. Resilience thinking is about how periods of gradual changes interact with abrupt changes, and the capacity of people, communities, societies, cultures to adapt or even transform into new development pathways in the face of dynamic change. It is about how to navigate the journey in relation to diverse pathways, and thresholds and tipping points between them. In resilience thinking, adaptation refers to human actions that sustain development on current pathways, while transformation is about shifting development into other emergent pathways and even creating new ones. (FOLKE, 2016, p.02)

Para Jabareen (2013), a resiliência, no contexto urbano, é a maneira como os sistemas ecológicos lidam com perturbações de fatores externos. Nesse pluralismo conceitual, o termo resiliência vem sendo utilizado no contexto das cidades na busca por uma melhor qualidade de vida de seus habitantes, frente às incertezas ocasionadas pela falta de 
planejamento e ordenamento das cidades, somado, também, à ocorrência esporádica de fenômenos ambientais. Uma cidade resiliente, de acordo com Gonçalves (2017, p.377-378), "corresponde a uma rede sustentável de sistemas físicos e de comunidades humanas", como também "pode ser vista como sendo a que é capaz de gerar, nos seus sistemas, competências para lidar com ameaças à sua sobrevivência e recursos para se autossustentar".

No cenário atual de cidades construídas para o aporte industrial e de serviços, pensar na resiliência urbana é também refletir em como o ser humano está inserido no ecossistema, como as populações promovem e vivem a cidade. A cidade, sendo um sistema aberto e suscetível a eventos adversos que promovem a vulnerabilidade e, consequentemente, geram riscos, deve ser pensada para aqueles que a vivem. Pensar em medidas de mitigação, auto-organização e adaptação é uma das formas de se conseguir a resiliência.

Segundo Carvalho et.al (2013, p.443), “a cidade resiliente é menos vulnerável e assume uma melhor preparação para lidar com a mudança, com a complexidade de riscos existentes, com crises e perturbações múltiplas, evitando disrupções e colapsos, como consequência de um desastre". Percebe-se, então, que a construção de cidades resilientes frente às cidades que já estão formadas é um desafio, pois essas cidades enfrentam diversos problemas urbanos, como resulta da leitura da publicação da Organização das Nações Unidas (ONU) "Como construir cidades mais resilientes, um guia para gestores públicos locais", publicado em 2012, com o intuito "de apoiar as políticas públicas, os processos decisórios e a organização para implantação de atividades de redução de riscos de desastres e de resiliência" (ONU, 2012, p.7).

Segundo Acselrad (2009), no entanto, não é somente o discurso da resiliência que deve ser levado em conta para a construção de uma cidade com novos parâmetros, mas também:

Pensar um novo modelo de desenvolvimento urbano, baseado nos princípios da democratização dos territórios, no combate a segregação socioespacial, na defesa dos direitos de acesso aos serviços urbanos e na superação da desigualdade social manifesta também nas condições de exposição aos riscos urbanos (ACSELRAD, 2009, p.39-40).

Sendo assim, a resiliência urbana não deve ser pensada somente pelos gestores das cidades, mas, também, por aqueles que a fazem cidade, ou seja, seus cidadãos. Nesse sentido, atividades de conscientização da população e participação popular na tomada de decisões 
das políticas públicas podem tornar mais simples e eficaz a mudança que a cidade precisa para se tornar mais resiliente.

Como afirma, Rattner (2009, p.16):

[...] uma vez que a comunidade se torne protagonista de sua história, as prioridades são facilmente redefinidas e as necessidades sociais são trazidas para o primeiro plano pelos sujeitos que as sintam e experimentem. Saneamento básico, pavimentação de estradas, escolas e creches, habitação e centros de saúde se impõem, em contraste com os modelos de consumo supérfluo e de desperdício.

Uma cidade resiliente, de acordo com Jabareen (2013, p.227):

resilient city is defined by the overall abilities of its governance, physical, economic and social systems and entities exposed to hazards to learn, be ready in advance, plan for uncertainties, resist, absorb, accommo date to and recover from the effects of a hazard in a timely and efficient manner, including through the preservation and restoration of its essential basic structures and functions.

Portanto, a construção de uma cidade resiliente, ou tornar as cidades mais resilientes nos dias atuais, obrigam a se refletir sobre aqueles que vivem as cidades, os seus sistemas sociais, econômicos e culturais. E a pensar, além disso, nos fenômenos adversos que uma qualquer localidade enfrentou ou vem enfrentando para conseguir uma melhor capacidade de autoadaptação e organização.

\section{Resultados e discussões}

A busca por cidades resilientes é uma das metas estipuladas pela ONU até 2030, por meio de campanhas mundiais. Essa meta sugere aos governos (global, regional e local) repensar a maneira como as cidades vêm sendo construídas e (re)produzidas, com o intuito de melhorar a qualidade de vida dos seus habitantes.

Entende-se que as desigualdades levem a configurar situações de injustiças ambientais, constituindo-se em um dos desafios na busca de uma cidade resiliente. Assim, aquelas pessoas que possuem um menor poder aquisitivo estão mais sujeitas a sofrerem mais as consequências de fenômenos adversos da natureza, bem como aqueles que, sendo de natureza ambiental, são produzidos pelos seres humanos, tais como os associados a lixo, efluentes e falta de saneamento básico. 
Dados do International Bank for Reconstruction and Development (IBRD, 2016) indicam que 767 milhões de pessoas em 2013 ainda vivem com menos U\$ 1,90 por dia. Apesar disso, houve a redução da pobreza em todo o mundo, em que cerca de 1,1 bilhão de pessoas deixaram a pobreza desde 1990, segundo a Organização da Nações Unidas.

O Brasil durante o período de 2002 a 2015, através de políticas sociais de caráter redistributivo e inclusão, além da estabilidade econômica e de um certo grau de desenvolvimentismo, impactou significativamente na redução da pobreza no país e no número absoluto da pobreza mundial. Entretanto, ainda assim, um dos fatores que impulsionam a manutenção da pobreza, de acordo com IBRD (2016), é a desigualdade existente na distribuição dos bens para que haja uma melhor qualidade de vida. Destarte, uma das maneiras para a diminuição dessa desigualdade é a implantação de políticas públicas eficientes.

Nesse quadro, percebe-se o quanto a população e as políticas públicas devem estar envolvidas na busca por uma melhor qualidade de vida urbana e também na redução das desigualdades. A busca por uma cidade resiliente é uma das maneiras de se chegar a esse objetivo. Se há a distribuição desigual dos "bens" sociais e naturais e se há uma parcela da população especialmente vulnerável aos riscos ambientais e sociais, faz-se pensar em uma estratégia para o combater. Diante disso, a ONU já lançou 10 (dez) passos para se construir uma cidade resiliente, são eles:

1. Coloque em prática ações de organização e coordenação para compreender e aplicar ferramentas de redução de riscos de desastres, com base na participação de grupos de cidadãos e da sociedade civil. Construa alianças locais. Assegure que todos os departamentos compreendam o seu papel na redução de riscos de desastres e preparação.

2. Atribua um orçamento para a redução de riscos de desastres e forneça incentivos para proprietários em áreas de risco, famílias de baixa renda, comunidades, empresas e setor público para investir na redução dos riscos que enfrentam.

3. Mantenha os dados sobre os riscos e vulnerabilidades atualizados. Prepare as avaliações de risco e utilize-as como base para planos de desenvolvimento urbano e tomadas de decisão. Certifique-se de que esta informação e os planos a resiliência da sua cidade estejam prontamente disponíveis ao público e totalmente discutido com eles.

4. Invista e mantenha uma estrutura para redução de risco, com enfoque estrutural, como por exemplo, obras de drenagem para evitar inundações; e, conforme necessário, invista em ações de adaptação às mudanças climáticas. 
5. Avalie a segurança de todas as escolas e centros de saúde e atualize tais avaliações conforme necessário.

6. Aplique e imponha regulamentos realistas, compatíveis com o risco de construção e princípios de planejamento do uso do solo. Identifique áreas seguras para cidadãos de baixa renda e desenvolva a urbanização dos assentamentos informais, sempre que possível.

7. Certifique-se de que programas de educação e treinamento sobre a redução de riscos de desastres estejam em vigor nas escolas e comunidades.

8. Proteja os ecossistemas e barreiras naturais para mitigar inundações, tempestades e outros perigos a que sua cidade seja vulnerável. Adapte-se à mudança climática por meio da construção de boas práticas de redução de risco.

9. Instale sistemas de alerta e alarme, e capacidades de gestão de emergências em seu município, realize regularmente exercícios públicos de preparação.

10. Após qualquer desastre, assegure que as necessidades dos sobreviventes estejam no centro da reconstrução, por meio do apoio direto e por suas organizações comunitárias, de modo a projetar e ajudar a implementar ações de resposta e recuperação, incluindo a reconstrução de casas meios de subsistência. (ONU, 2012, p.26)

Percebe-se, então, que para se construir ou até se alcançar o objetivo de uma cidade resiliente, deve-se perpassar por todas as instâncias, desde os gestores até a população, pois estes últimos são os que ali moram e que têm consciência de suas necessidades. Como bem afirma Rattner (2009), a partir do momento que a comunidade se torna agente de sua mudança e participa do processo de tomada de decisão, é que se consegue alcançar uma maior justiça e solidariedade na gestão pública.

Assim, é com o apoio da população que as cidades podem vir a se tornar mais resilientes, com uma gestão participativa que tornará o governo mais transparente. No caso brasileiro, iniciativas de boas práticas de governança podem ser observadas a partir do aumento de mecanismos de controle social estimulados a partir da abertura democrática e ratificados com a Constituição Federal de 1988. Alguns exemplos são as audiências públicas, como espaços de discussão e participação da população em políticas públicas, que interferem em suas condições de vidas. Instrumentos para acompanhamento da transparência pública vêm crescendo em todo país, assim como pesquisas e índices para medir o grau de governança pública (OLIVEIRA e PISA, 2015).

Diante do contexto das desigualdades e na busca por cidades resilientes, pode-se entender que a cidade, enquanto um sistema complexo e dinâmico, deve ser pensada não somente por um viés, como, por exemplo, um programa para melhoria do saneamento básico, mas 
em sua totalidade. É fundamental pensar em como pode vir a se adaptar diante de um fenômeno extremo e de como ele modificará a vida das pessoas que moram no seu entorno, ou que foram atendidas por essa ação governamental. Nesse sentido, Furtado (2015) afirma que apesar da resiliência, no âmbito das cidades, ser pensada como a capacidade de adaptação/tolerância/reorganização de uma população frente a um evento adverso, ela também demonstra um grau de disfunção, só sendo alcançada quando se consegue "voltar a funcionar normalmente depois dessa disfunção" (FURTADO, 2015, p.25).

Portanto, a construção de uma cidade resiliente, livre de desigualdade ambiental ou, ao menos, com essa e outras desigualdades amenizadas, significa pensar em estratégias de melhoria da qualidade de vida urbana em que sejam incluídos tanto os órgãos governamentais, quanto a sociedade, tendo em vista que quem nela vive esteja mais preparado para os desastres que possam vir a acontecer e a livrar-se da situação de vulnerabilidade.

\section{Considerações finais}

O crescimento das populações, a urbanização acelerada, os governos enfraquecidos, a instalação de domicílios em lugares impróprios, a concentração de renda na mão de poucos e os impactos causados ao meio ambiente são alguns dos fatores que promovem a desigualdade ambiental e levam a situações de vulnerabilidade das cidades e de boa parte dos seus habitantes.

No contexto da sociedade em que vivemos, diminuir as desigualdades, sociais, culturais, econômicas e ambientais é um desafio que parece cada vez mais difícil. A busca desenfreada por novos mercados, novas fontes de recursos naturais e mão de obra mais barata, dificulta a amenização desse quadro, principalmente nos países denominados em desenvolvimento, apesar de algumas notáveis exceções. Essa busca crescente por novos mercados e fontes de matéria-prima, sobretudo com o grande crescimento econômico de grandes nações, como a China e a Índia, estrangulam os ecossistemas socioambientais, potencializando como consequência os fenômenos naturais adversos. 
A maioria dos trabalhos consultados, que abordam a temática da resiliência nas cidades, está ligada à redução de desastres e riscos aos quais a população está ameaçada. Entretanto, ao final de todo esse diálogo, compreendendo que as cidades são sistemas complexos e dinâmicos e que todos que nela vivem compõem uma totalidade, cabe refletir a resiliência não somente em momentos em que a sociedade é acometida por algum desastre, mas considerar o processo de resiliência em todo o contexto urbano e processo de evolução da cidade, por exemplo na apropriação de espaços inadequados, no descarte inadequado de produtos produzidos por empresas e instituições fabris, entre tantos outros problemas da urbanidade.

Construir cidades mais preparadas para os diversos tipos de desastres, ou ao menos repensar a maneira como as cidades vêm sendo (re)produzidas, é essencial para o alcance da resiliência. Conscientizar a população dos riscos a que estão suscetíveis e integrá-la aos processos de tomada de decisão é um dos caminhos; o outro, não menos importante, passa pela diminuição das desigualdades, incluindo necessariamente uma maior igualdade perante o risco ambiental e a resiliência.

\section{Referências bibliográficas}

ACSELRAD, Henri; MELLO, Cecilia Campelo do Amaral; BEZERRA, Gustavo das Neves. O que é justiça ambiental. Rio de Janeiro: Garamond. 2009. 9788576171591

ACSELRAD, Henri. Justiça ambiental e construção social do risco. In: Desenvolvimento e meio ambiente: riscos coletivos - ambiente e saúde. Curitiba-PR: Editora da UFPR, nำ, 2002.

ACSELRAD, Henri. A duração das cidades: sustentabilidade e risco nas políticas urbanas. Rio de Janeiro: Lamparina, 2009. 9788574900438

BRASIL. Constituição da república federativa do Brasil de 1988. Brasília. 1988. Disponível em: http://www.planalto.gov.br/ccivil 03/constituicao.htm

BECK, Ulrich. Sociedade de risco: rumo a uma outra modernidade. 2.ed. São Paulo: Ed.34, 2011. 9788843068142

BULLARD, Robert D. Dumping in Dixie: race, class and environmental quality. Boulder, Westview Press, 1990. 9780813319636

BULLARD, Robert D. (ed.) Confronting Environmental Racism: voices from the grassroots. Boston: South End Press, 1993. 978-0896084469 
CARVALHO, Luís; et al. Risco, desastre e resiliência - um desafio para a cidade de Amadora. In: IX Congresso da geografia portuguesa - geografia: espaço, natureza e sociedade. Universidade de Évora. 2013. Disponível em: http://www.preventionweb.nt/files/36750 36750riskdisasterandresilienceamado.pdf.

FERRY, Luc. A nova ordem ecológica: a árvore, o anima e o homem. Rio de Janeiro: DIFEL, 2009. 9789724112978

FURTADO, Fátima. Cidades resilientes: considerações conceituais. IN: FURTADO, Fátima; PRIORI JR, Luiz; ALCÂNTARA, Edinéia. Mudanças climáticas e resiliência de cidades. Recife: Pickimagem, 2015. p.19-30. 978-8569110-00-2

FOLKE, Carl. Reslience, In: Ecology \& society. №21. Disponível em:https://www.ecologyandsociety.org/vol21/iss4/art44/.

GIDDENS, Anthony. As consequências da modernidade. São Paulo: Unesp. 1991. 9780804718912

GONÇALVES, Carlos. Redes, cidades e comunidades resilientes: novos princípios de desenvolvimento. In: Urbe: Revista de gestão urbana. Vol.9. n.2. Curitiba, 2017.

IRBD, International Bank for Reconstruction and Development. Poverty and share prosperity 2016: taking on inequality. The World Bank Group. Washington-DC. 2016. Disponível em: http://www.worldnank.org/en/publication/poverty-and-shared-prosperity

JABAREEN, Yosef. Planning the resilient citie: concepts and strategies for coping with climate change and environmental risk. In: Elsevier - cities. n.31. Disponível em: http://www.arhns.uns.ac.rs/wpcontent/uploads/planning-the-resilient-city.pdf

LEFEBVRE, HENRI. O direito à cidade. São Paulo: Centauro, 2001. 9788588208971

MARTÍNEZ ALIER, Juan. O ecologismo dos pobres: conflitos ambientais e linguagens de valoração. São Paulo: Contexto, 2009. 9788572443586

MORATO, Rúbia Gomes. Análise espacial e desigualdade ambiental no município de São Paulo. 2008. 154f. Tese de doutorado (Doutorado em Geografia Humana) - Faculdade de Filosofia, Letras e Ciências Humanas. Universidade de São Paulo, São Paulo.

OLIVEIRA, A. G; PISA, B. J. IGovP: índice de avaliação da governança pública - instrumento de planejamento do Estado e de controle social pelo cidadão. In: Rev. Adm. Pública. 2015, vol.49, n.5, pp. 1263-1290. ISSN 00347612. DOI: 10.1590/0034-7612136179. Disponível em:http://ref.scielo.org/ynvcxz

ORGANIZAÇÃO DAS NAÇÕES UNIDAS. Como construir cidades mais resilientes: um guia para gestores públicos locais. Genebra, 2012. Disponível em: http://www.unisdr.org/files/26462_guiagestorespublicosweb.pdf.

RATTNER, Henrique. Prefácio. In: ACSELRAD, Henri. A duração das cidades: sustentabilidade e risco nas políticas urbanas. 2.ed. Rio de Janeiro: Lamparina, 2009. 9788574900438

RIBEIRO, LUIZ C. de Q.; RIBEIRO, MARCELO G (Orgs.). Metrópoles brasileiras: sínteses da transformação na ordem urbana 1980 a 2010.Rio de Janeiro: Letra Capital, Observatório das Metrópoles, 2018.

SANTOS, Milton. A natureza do espaço: técnica e espaço, razão e emoção. São Paulo: Editora da Universidade de São Paulo. 2012. 9788531407130.

VASCONCELOS, Pedro de Almeida. Contribuições para o debate sobre processos e formas socioespaciais nas cidades. In: VASCONCELOS, Pedro de Almeida; CORRÊA, Roberto Lobato; PINTAUDI, Silvana Maria. A cidade contemporânea: segregação espacial. São Paulo: Contexto, 2015. p.17-37. 9788572448161

TORRES, Haroldo da Gama. Desigualdade ambiental na cidade de São Paulo. 1997. 286f. Tese de doutorado (Doutorado em Ciências Sociais) - Intituto de Filosofia e Ciências Humanas. Universidade de Campinas, São Paulo. 
UNIKEL, Luis Spector. El desarrollo urbano no México: diagnóstico e implicações futuras.Ciudad de México: El Colegio de México, Centro de Estudios Económicos y Demográficos, 2016. 9786074629514 